\title{
Event-based control of basic wastewater treatment plant control loops
}

\author{
R. Vilanova, I. Santin, C. Pedret \\ UAB, Barcelona, \{Ramon.Vilanova, Ignacio.Santin, Carles.Pedret\}@uab.cat \\ M. Barbu \\ "Dunarea de Jos" University of Galati. Romania Marian.Barbu@ugal.ro
}

\begin{abstract}
This paper addresses the problem of basic control loops in wastewater treatment plants. By basic control loops we are referring to the traditional dissolved oxygen and nitrates. They are the basic controls more sophisticated control solutions can be based upon. Therefore it is important that these loops perform in an efficient way. The problem is addressed here within the framework provided by the Benchmark Simulation Model Number 1 (BSM1) and by the use of an event-based solution. It will be verified that the solution can slightly improve the performance of the already exiting controllers both at loop level as well as at plant operation level.
\end{abstract}

Keywords: Event-based control, Nutrient removal, Wastewater treatment plants.

\section{Introduction}

The increasing human activities have generated the need of using appropriate methods to reduce their impact on the environment. One of the essential components of this effort is the implementation of wastewater treatment plants in order to bring the effluent to acceptable pollutant concentration limits before it is discharged into natural recipients (lakes, rivers etc.). Wastewater treatment plants (WWTPs) are used worldwide to ensure the suitable water quality for the receiving environment. Some of the pollutants are reduced to allowed levels by the default WWTP structure without applying any automatic control. However, other pollutants are more difficult to be reduced. For this reason and also to restrict operational costs, the application of control engineering in WWTPs is playing an important role in research in recent years [1] and [2].

An efficient solution to improve the efficiency of wastewater treatment plants is to adopt automatic control methods. [3, 4, 5]. Their adoption for these systems is slow in the case of wastewater treatment plants, the main reasons being, on one hand, the fact that they are extremely complex processes and the lack or the high cost of the measurement equipment, and on the other hand, the significant reticence of the industry to allow the testing of the control solutions on real plants, given the potential environmental risks [6]. Nevertheless, a few cases of plant automation, made possible by new monitoring instrumentation, [7] have been recently cited in the literature, $[8]$ and more are being gradually implemented in full-size facilities.

Another proposed solution is to build some benchmark models which allow different users to test their control structures and algorithms on the same platform. A first model is the Benchmark Simulation Model No. 1 (BSM1)[9] which includes only water processing units and defines three scenarios for the influent, based on the rain conditions that may arise. BSM1 includes a control strategy that is called Default Control Strategy (DCS). This is based on PI controllers in order to control the dissolved oxygen in the fifth tank $(\mathrm{DO} 5)$ and the nitrate in the second tank $(\mathrm{NO} 2)$ by manipulating the oxygen transfer coefficient in the fifth tank $\left(K L a_{5}\right)$ and the internal recycle flow rate $\left(Q_{\text {rin }}\right)$ respectively. Obtaining a satisfactory control performance of these variables is of great importance, especially when applying more complex control strategies that vary the set-points of the default control loops. In these cases, with better performance of the default control loops, effluent quality is improved with lower costs. In this way, for several years and still recently there are many works that focus on the objective of improving the performance of $\mathrm{DO} 5$ and $\mathrm{NO} 2$ control, as in [10] and [11].

The present work is based mainly on the application of event-based control in order to improve the performance of DCS. Event-based control is a technique already used in other areas such as in [12] for $\mathrm{pH}$ control for the effective use of flue gases or in [13] for greenhouse production processes. However, it is a novelty in the literature related to Wastewater Treatment Plant control. In common control techniques, the control signal is actualised based on time. In the case of eventbased controllers, the verification of events is reg- 
ularly carried out, but the control signal is only actualised when one or more events occur.

The rest of te paper is as follows. First of all, the simulation scenario is presented. The BSM1 layout, performance indexes and default control strategy is presented. Secondly, in section 3, the event-based control strategy based on the internal model control formulation is outlined. This generic structure was first presented in [14] in more detail, so just the basic structure and design principles are outlined here. It follows section 4 with the definition of the event based controllers for the BSM1 basic loops and presentation of the simulation results, The paper ends with concluding remarks and suggestions for further work.

\section{Materials And Methods}

This section presents the basic elements that constitute the working scenario. On one side, the wastewater plant layout and evaluation indexes that will be used to assess the control strategies. Also the generic event-based control approach based on the IMC event-based presented in [14] will be presented.

\subsection{Benchmark Simulation Model \#1}

This section provides a brief description of the working scenario provided by the BSM1. This is a simulation environment defining a plant layout, a simulation model, influent loads, test procedures and evaluation criteria.

\subsection{Plant layout and Influent loads}

The schematic representation of the WWTP is presented in Fig.1. The plant consists in five biological reactor tanks connected in series, followed by a secondary settler. The first two tanks have a volume of $1000 \mathrm{~m}^{3}$ each and are anoxic and perfectly mixed. The rest three tanks have a volume of $1333 \mathrm{~m}^{3}$ each and are aerated. The settler has a total volume of $6000 \mathrm{~m}^{3}$ and is modeled in ten layers, being the 6th layer, counting from bottom to top, the feed layer. Two recycle flows, the first from the last tank and the second from the underflow of the settler, complete the system. The plant is designed for an average influent dryweather flow rate of $18446 \mathrm{~m}^{3} / \mathrm{d}$ and an average biodegradable chemical oxygen demand (COD) in the influent of $300 \mathrm{~g} / \mathrm{m}^{3}$. Its hydraulic retention time, based on the average dry weather flow rate and the total tank and settler volume $\left(12000 \mathrm{~m}^{3}\right)$, is $14.4 \mathrm{~h}$. The default wastage flow rate $\left(\mathrm{Q}_{w}\right)$ is fixed to $385 \mathrm{~m}^{3} / \mathrm{d}$ that determines, based on the total amount of biomass present in the system,

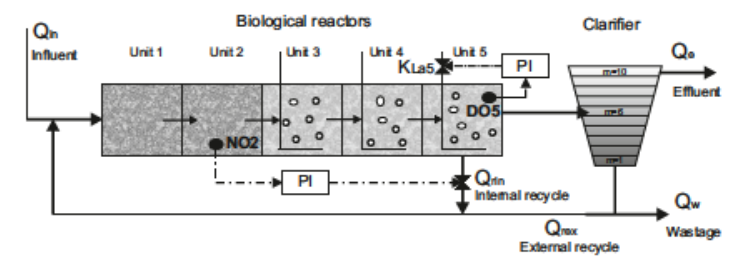

Figure 1: Benchmark Simulation Model 1 with default control strategy on the basic loops

a biomass sludge age of about 9 days. The nitrogen removal is achieved using a denitrification step performed in the anoxic tanks and a nitrification step carried out in the aerated tanks. The internal recycle is used to supply the denitrification step with NO. BSM1 defines three different influent data $[15,16]$ : dry weather, rain weather and storm weather. Each scenario contains 14 days of influent data with sampling intervals of $15 \mathrm{~min}$ utes.

\subsubsection{Test procedures}

A simulation protocol is established to assure that results are got under the same conditions and can be compared. So first a 150 days period of stabilization in closed-loop using constant influent data has to be completed to drive the system to a steady-state, next a simulation with dry weather is run and finally the desired influent data (dry, rain or storm) is tested. Only the results of the last seven days are considered.

\subsubsection{Evaluation criteria}

In order to compare the different control strategies, different criteria are defined.

The performance assessment is made at two levels. The first level concerns the control. Basically, this serves as a proof that the proposed control strategy has been applied properly. It is assessed by Integral of the Squared Error (ISE) and integrated absolute error (IAE) criterias. The second level provides measures for the effect of the control strategy on plant performance. It includes Effluent Quality Index (EQI) and Overall Cost Index (OCI).

\begin{tabular}{|c|c|}
\hline Variable & Value \\
\hline $\mathrm{N}_{\text {tot }}$ & $<18$ g N.m $^{-3}$ \\
\hline $\mathrm{COD}_{t}$ & $<100$ g COD.m $^{-3}$ \\
\hline $\mathrm{NH}$ & $<4$ g N.m $^{-3}$ \\
\hline TSS & $<30{\mathrm{~g} \mathrm{SS} . \mathrm{m}^{-3}}^{-3}$ \\
\hline $\mathrm{BOD}_{5}$ & $<10$ g BOD. $\mathrm{m}^{-3}$ \\
\hline
\end{tabular}

Table 1: Effluent quality limits 
The evaluation must include the percentage of time that the effluent limits are not met and the number of violations. This last term is defined as the number of crossings of the limit, from below to above the limit. The effluent concentrations of $\mathrm{N}_{\text {tot }}$, Total COD $\left(\mathrm{COD}_{t}\right), \mathrm{NH}$, Total Suspended Solids (TSS) and Biological Oxygen Demand $\left(\mathrm{BOD}_{5}\right)$ should obey the limits given in Table 1. $\mathrm{N}_{\text {tot }}$ is calculated as the sum of $\mathrm{NO}$ and Kjeldahl nitrogen $(\mathrm{NKj})$, being this the sum of organic nitrogen and $\mathrm{NH}$.

For what matters to the global plant operation evaluation the Effluent Quality Index, EQI, is defined to evaluate the quality of the effluent. It is related with the fines to be paid due to the discharge of pollution. EQI is averaged over a 7 days observation period and it is calculated weighting the different compounds of the effluent loads. On the other hand, the Overall Cost Index, OCI, is defined as:

$$
O C I=A E+P E+5 \cdot S P+3 \cdot E C+M E
$$

where $\mathrm{AE}$ is the aeration energy, $\mathrm{PE}$ is the pumping energy, SP is the sludge production to be disposed, EC is the consumption of external carbon source and ME is the mixing energy. For a complete specification of these indexes and its concrete computation, the reader is referred to [15].

\subsubsection{Default control strategy}

The definition of the BSM1 include a default control strategy, which is commonly used as a reference for comparison. The default control strategy of BSM1 [9] uses two Proportional-Integral (PI) control loops as shown in Fig. 1. The first one involves the control of $\mathrm{S}_{O, 5}$ by manipulating $\mathrm{K}_{L}$ a in the fifth tank $\left(K_{L} a_{5}\right)$. The set-point for $S_{O, 5}$ is $2 \mathrm{mg} / \mathrm{l}$. The second control loop has to maintain $\mathrm{S}_{\mathrm{NO}, 2}$ at a set-point of $1 \mathrm{mg} / \mathrm{l}$ by manipulating $\mathrm{Q}_{a}$.

\subsection{Event-based Internal Model Control}

The Internal Model Control (IMC) approach for controller design as presented in [17] and further developed in [18] is based on the very basic principle of close the loop when necessary. This is also one of the essentials of event-based control. An event will be generated just in case there is the need to feed the controller with new information regarding the process output and to use this information to change the control action. In this section we will provide a quick review of the IMC basics with special emphasis on the conceptual meaning of the different key signals in order to see that, even on a continuos time basis ${ }^{1}$, the event-based rationale is inherent to the IMC structure. This is not the case of the classical feedback control configuration.

The IMC scheme is based on the notion of feeding back the uncertainty to the IMC controller. If there is no uncertainty there is no need to close the system other than to stabilize it. Therefore, in the case the process to be controlled is open-loop stable, the requirement of accurate set-point tracking can be achieved by an open loop control system. With an open loop control scheme, the stability of the system is guaranteed provided that both the plant and controller transfer functions are stable. Also, the design of the controller in an open loop control scheme may simply be approached by dynamic inversion. The drawback of such an open loop control system is the sensitivity to modeling errors and the inability to deal with external disturbances entering the system. In fact, an external, not measurable, disturbance can easily be assimilated to a kind of uncertainty. In this case, the only way to inform the controller of the effects of the uncertainty on the controlled variable is by the use of feedback. Therefore, a closed-loop system should be used to deal with uncertainty whatever its source. The IMC control scheme, depicted in figure (2(a)) obeys to the previous principle.

Within the conventional IMC structure, where $P$ is the process to be controlled, $P_{m}$ represents the model of the process, and $Q$ is the IMC controller. The signal that is feedback to the controller to form the, in a confuse way called, error. It is given by:

$$
\begin{aligned}
e & =r-y+P_{m} u=r-P(u+d)+P_{m} u-(2) \\
& =r-P d+\left(P_{m}-P\right) u-n
\end{aligned}
$$

where obviously if there are no modeling errors, $P_{m}=P$, and there is no external disturbance, $d=0$, nor measurement noise, $n=0$, the feedback is zero and the system operates in open-loop. In such case, the IMC controller is just driven by the reference signal. It is just when uncertainty in any one of the previous forms appears that the feedback signal is different from zero in order to inform the IMC controller of it.

We can think of this situation in event terms. The appearance of uncertainty is like signaling an event that forces to close the loop. We can extend this rationale and consider the need to close the loop just when the uncertainty is significant, say it is above some threshold. This is what let $\mathbf{s}$ to propose the event-based scheme shown in figure (2(b)).

\footnotetext{
${ }^{1}$ the same applies if we work on a sampled, discrete time, control system.
} 


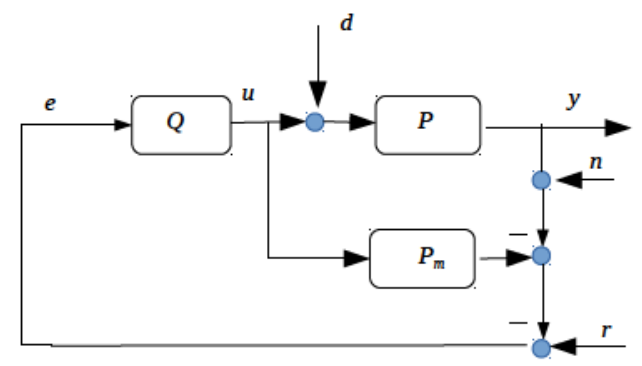

(a)Conventional Internal Model Control Configuration

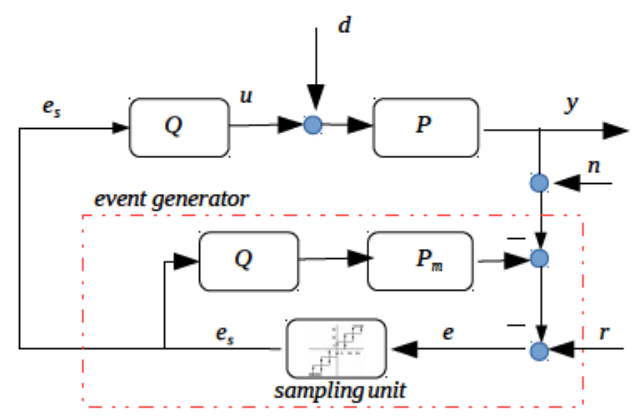

(b) Event-based Internal Model Control Configuration

Figure 2: Conventional and event-based Internal Model Control configurations

In this scheme, apart from the IMC controller, $Q$, the rest is considered to be part of the event generator. Therefore, the event generator includes the plant model, $P_{m}$, as well as a replica of the controller. The other unit of the event generator is the sampling unit. The aim of this block is to measure and to send an error sample to the controller each time the event condition is satisfied. For this purpose the SSOD sampling algorithm introduced in [19] has been considered. However, the key properties of the event-based IMC are to be independent of this choice. According to the standard algorithm, the output is computed based on two predefined parameters: an event threshold $\Delta \in \mathbb{R}^{+}$, and the internal state of the algorithm $j \in \mathbb{Z}^{+}$. Therefore, if $e(t)$ is the input to the SSOD block, its output is computed according to $e_{s}(t)=j \Delta$. In this way the events are triggered when consecutive levels are crossed by the error signal, which means that the sampled signal changes its value to the upper or lower quantization level when the input signal $e(t)$ increases or decreases more than $\Delta$.

The closed-loop response of an event-based control system is driven by the occurrence of the events. As long as no new event is generated, the input to the IMC controller $Q$ will be kept to its actual value $e_{s}(t)=j \Delta$ and the control system will operate in open loop. From the expression (3) of the signal being sampled, it is the presence of any sort of uncertainty that may drive the generation of an event. The behavior of the system can therefore be assimilated to a sequence of open-loop responses of the form $y_{j}(s)=P(s) Q(s) j \Delta$. As per the properties of the IMC this will always be a stable open loop as long as the IMC controller and the plant are stable.

\section{Event-Based Controllers Design}

In this section, we present the design of the eventbased IMC controllers to the two basic control loops defined in the BSM1 scenario. For such purpose, in what follows, the design of the controllers is presented first as usual continuous time IMC controllers, followed by its implementation under an event-based strategy.

\subsection{Internal Model Controllers}

In this section the design of the $D O$ controller for the fifth aerated tank, $D O_{5}$, as well as for the nitrate on the second tank, $\mathrm{NO}_{2}$ are considered. For controller design purposes, a linear model is derived first for each one of the loops. In order to facilitate the implementation of the controller as well as minimise impact on plant operation the required experiments to identify the models are designed as simple as possible. The experiment carried out is to drive the system to a steady state situation and to apply a $10 \%$ step change in the manipulated variables. The resulting data is collected and used for identification. The linear process models were obtained using subspace identification techniques. The algorithm employed was N4SID [20], which exhibits robust numerical properties and relatively low computational complexity. As usual within the Proces Control community, whenever possible, these models will be reduced to the usual First-Order-Plus-time-Delay (FOPTD) or even just First-Order (FO) in order to facilitate the application of simple controller tuning rules. Here the following First Order model is obtained for the relation from the $K L a_{5}$ to the $\mathrm{DO}_{5}$ :

$$
P_{D O_{5}}(s)=\frac{K_{D O 5}}{T_{D O 5} s+1}=\frac{0.0163}{0.01 s+1}
$$

As a complement to the $\mathrm{DO}_{5}$ control on the last aerated tank, the Benchmark framework proposes the control of the nitrate on the second tank, $\mathrm{NO}_{2}$, by using the internal recirculating flow, $Q_{\text {rin }}$. The $\mathrm{NO}_{2}$ controller will also be tuned according to the IMC approach but now using the corresponding identified model. The procedure follows the same lines as the one for the $D O$ controller in the previous section and the model that will be used for control is: 


$$
P_{\mathrm{NO}_{2}}(s)=\frac{K_{\mathrm{NO} 2}}{T_{\mathrm{NO} 2} s+1}=\frac{7.914510^{-5}}{0.02 s+1}
$$

As it can be observed, the models have been reduced to the minimum complexity. No higher order models are needed. As a side benefit, the corresponding controllers will also be very simple from both the design point of view as well as the implementation one.

The design of the corresponding IMC controllers, follows the usual procedure. In IMC control, if $P(s)$ denotes the process model, the IMC controller $Q(s)$ is expressed as:

$$
Q(s)=P(s)^{-1} F(s)=P(s)^{-1} \frac{1}{(\lambda s+1)^{n}}
$$

where $F(s)$ is the well known IMC filter. The $\lambda$ parameter, determines the closed-loop time constant. This time constant can be selected on the basis of the open-loop time constant, $T$, as $\lambda=\tau_{c} T$, where $\tau_{c}$ expresses the speed of response of the closed-loop with respect to the open-loop. Here, we select the desired closed-loop tome constant as ten times faster. Therefore, for both loops, $\tau_{c}=0.1$. The resulting IMC controllers read as:

$$
Q_{x}(s)=P_{x}(s)^{-1} F_{x}(s)=\frac{\left(T_{x} s+1\right)}{K_{x}} \frac{1}{\left(T_{x} \tau_{c} s+1\right)^{2}}
$$

where $x$ stands for $\mathrm{DO} 5$ and $\mathrm{NO} 2$ in each case.

At this point it is worth to notice that, even the design of the controller is presented within the IMC framework, the presented controllers are, in fact, filtered PI controllers. Therefore, the same kind of control law as the ones implemented in the benchmark.

Effectively, the feedback controller $K_{x}(s)$ associated to $Q_{x}(s)$ reads

$$
\begin{aligned}
K_{x}(s) & =\frac{T_{x} s+1}{K_{x}} \frac{1}{\lambda_{x}^{2} s^{2}+2 s \lambda_{x}} \\
& =\frac{2 T_{x}}{K \lambda_{x}}\left(1+\frac{1}{T_{x} s}\right) \frac{1}{\lambda_{x} / 2 s+1}
\end{aligned}
$$

This is a PI controller with parameters $K_{p}=$ $\left(2 T_{x} / K_{x} \lambda_{x}\right), T_{i}=T_{x}$ and filtered with a low pass filter with time constant $\lambda_{x} / 2$. Therefore, at the end, it can be seen either as a PI or as an IMC.

\subsection{Event-based implementation}

For the event-based implementation, we just need to specify the sampling time of the event generator and the precision interval that will determine the event quantisation. As the order of magnitud of both loops is the same, the precision interval for event detection has been chosen as $\Delta_{D O 5}=\Delta_{N O 2}=\Delta=0.01$. Also, the the sampling time of for event detection has been fixed to $1 \mathrm{~min}$. This means that a process measurement will be taken every minute and the event-detection will be executed. If no event is detected then no signal will be transmitted to the actuator.

These settings arise quite naturally from the dynamics of the loops under consideration. The selection of these parameters will determine the track following capabilities of the corresponding loop. Notice whereas the controllers defined in the default control strategy do operate in continuous time here the manipulated variable moves are driven by the generation of the corresponding events.

As a matter of comparison, the PI controller parameters that would result from translating the IMC designs into its PI form are compared with the PI tuning specified in the benchmark. Table (2) shows both tunings. It is observed that the event-based implementation allows higher controller gains that are traduced into better tracking and faster disturbance attenuation.

Table 2: PI controller tunings

\begin{tabular}{|l|c|c|c|c|}
\hline \multirow{2}{*}{ Loop } & \multicolumn{2}{|c|}{ Proposed } & \multicolumn{2}{c|}{ Benchmark } \\
\cline { 2 - 5 } & $K_{p}$ & $T_{i}$ & $K_{p}$ & $T_{i}$ \\
\hline DO5 & 1.227 & 0.01 & 25 & 0.002 \\
\hline SNO2 & 25.2700 & 0.02 & 10.000 & 0.025 \\
\hline
\end{tabular}

\section{Simulation results}

In this section, we present the application of the designed event-based IMC control to the two basic control loops defined in the BSM1 scenario. The motivation in showing this application is also to show the fact that the design of the controller can be addressed in a complete independent way from its event-based implementation. This is one of the main advantages of this method that allows the independent (re)adjustment of both parts of the control system .

The time responses as well as quantitative metrics that show the performance of the proposed controllers in comparison with the default controllers included in the benchmark. Here, just the time 
responses corresponding to the dry influent profile are shown. However, in table (3), the performance metrics corresponding to all three influents are shown and compared with the performance of the original benchmark default controller. It is worth to highlight that in the literature, the improvement in these two loops is usually addressed by the use of other , more advanced, control approaches such as model predictive control [21]. Here we show that there is still room for improvement if what is introduced is not a change in the computation of the control law itself but in its implementation. Here as event-driven controllers.

As with the established benchmark, one week of evolution is considered. Figures (3) and (4) show the evolution of fifth tank dissolved oxygen and second anoxic tank nitrates concentrations along with the corresponding manipulated variables. It can be seen that the tracking performance of the event-based controllers is superior to that one of the PI controllers provided by the benchmark. The benefits are remarkably better in the $\mathrm{NO} 2$ loop, where more accurate tracking is achieved. In the DO5 control loop, quite high precision is already achieved by the benchmark controller. In the solution provided here, in addition with the slight tracking error reduction, there is the fact that DO measures are needed with just one minute sampling. This point will allow, for example, the use of modern smart sensors with wireless communication capabilities by imposing lower data transmission needs.

The main impact of the event-based implementation can be seen in the manipulated variables. Whereas for the dissolved oxygen control loop, the control signal follows a very similar pattern (with very slight differences), the internal recirculation flow rate has higher bandwidth as the major responsible for the tracking improvement.

Figures (5) and (6) show a more detailed view of the operation of both loops during day 8th. As expected, the number of events is much more dense when the disturbance enters into effect and the controlled variable is driven away from the reference value. In both cases, it can be appreciated that when the controlled variable suffers high deviation from the reference value, an higher number of events are generated that corresponds to a more continuous control action (always within the established sample times) that is slightly anticipated with respect to the benchmark one.

A more quantitative performance comparison is shown in table (3) where the metrics provided by the BSM1 scenario are employed. Performance at both control loop and plant level are used. Effec- tively the tracking performance of both loops is clearly superior in absolute and aggregated terms. However, it is well known that sometimes, to achieve this increment in tracking performance at loop level, has small repercussions at plant level or event it may increase the overall costs at the expenses of not improving the plant treatment efficiency. In this case, the proposed controllers achieve a non despreciable improvement on the plant treatment capacity at the expenses of practically the same overall cost. Clearly, the average of effluent nutrient concentrations as well as effluent limit violations are slightly improved.
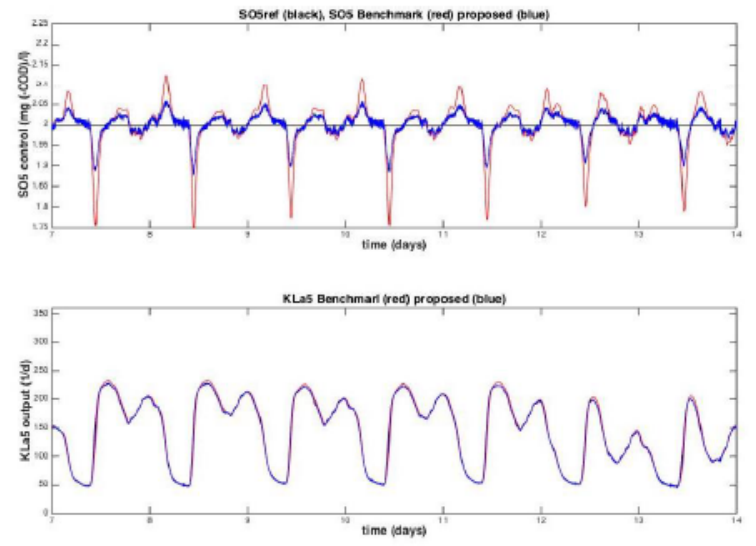

Figure 3: $\mathrm{SO}_{5}$ control loop performance and $K L a_{5}$ manipulated variable

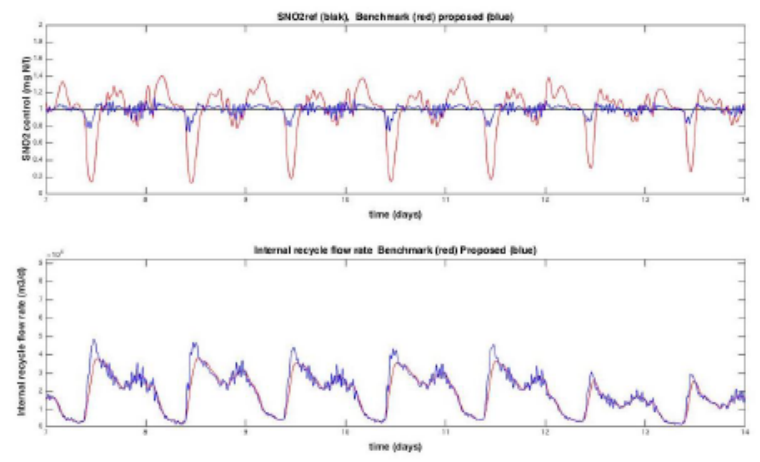

Figure 4: $\mathrm{SNO}_{2}$ control loop performance and $Q_{\text {intr }}$ manipulated variable

\section{Conclusions}

This paper has analysed the application of the event-based strategy for the control of the two basic loops in wastewater treatment plants. the event-based controllers are defined in terms of the IMC control formulation. This formulation provides the nice feature of allowing to select the basic controllers without the need to think into the event-based strategies. As a second step, the controller is implemented into the event-based formu- 
Table 3: Benchmark Default C ontrol (DC) and Event-Based (EB) control comparison.

\begin{tabular}{|c|c|c|c|c|c|c|}
\hline & \multicolumn{2}{|c|}{ Dry } & \multicolumn{2}{|c|}{ Rain } & \multicolumn{2}{|c|}{ Storm } \\
\hline & DC & $\mathrm{EB}$ & DC & $\mathrm{EB}$ & $\mathrm{DC}$ & EB \\
\hline \multicolumn{7}{|c|}{ NO2 loop } \\
\hline IAE $\left(g N / m^{3} d\right)$ & 1.25 & 0.26 & 1.57 & 0.40 & 1.52 & 0.40 \\
\hline ISE $\left(g N / m^{3}\right)^{2} d$ & 0.47 & 0.02 & 0.70 & 0.06 & 0.70 & 0.07 \\
\hline Max deviation $g N / m^{3}$ & 0.86 & 0.22 & 0.90 & 0.52 & 1.0 & 0.60 \\
\hline \multicolumn{7}{|c|}{ DO5 loop } \\
\hline IAE $g(-C O D) / m^{3} d$ & 0.25 & 0.14 & 0.21 & 0.12 & 0.24 & 0.13 \\
\hline ISE $\left(g(-C O D) / m^{3}\right) 2 d$ & 0.02 & 0.005 & 0.02 & 0.003 & 0.02 & 0.005 \\
\hline Max deviation $g(-C O D) / m^{3}$ & 0.26 & 0.11 & 0.24 & 0.1 & 0.26 & 0.11 \\
\hline \multicolumn{7}{|c|}{ Effluent average concentrations } \\
\hline SNH $\left(\right.$ limit $\left.=4 \mathrm{gN} / \mathrm{m}^{3}\right)$ & 2.53 & 2.45 & 3.21 & 3.35 & 3.05 & 3.07 \\
\hline TSS $\left(\right.$ limit $\left.=30 \mathrm{gSS} / \mathrm{m}^{3}\right)$ & 13,0 & 13.0 & 16.17 & 16.09 & 15.27 & 15.28 \\
\hline Total N (limit $=18 g N / l)$ & 16,89 & 16.74 & 14.71 & 14.65 & 15.83 & 15.70 \\
\hline Total COD $\left(\right.$ limit $\left.=100 \mathrm{gCOD} / \mathrm{m}^{3}\right)$ & 48,22 & 48.21 & 45.43 & 45.32 & 47.65 & 47.66 \\
\hline BOD5 $\left(\right.$ limit $\left.=10 \mathrm{~g} / \mathrm{m}^{3}\right)$ & 2,75 & 2.75 & 3.45 & 3.45 & 3.20 & 3.20 \\
\hline \multicolumn{7}{|c|}{ Quality / Cost variables } \\
\hline EQI (kg poll.units/day) & 6115,63 & 6058.26 & 8174.98 & 8216.17 & 7211.48 & 7190.45 \\
\hline OCI & 16381,93 & 16382.24 & 15984.5 & 16035.06 & 17253.75 & 17250.39 \\
\hline \multicolumn{7}{|c|}{ Effluent violations } \\
\hline $95 \%$ percentile of ef. SNH $\left(\mathrm{gN} / \mathrm{m}^{3}\right)$ & 7.36 & 7.02 & 8.03 & 8.0 & 7.76 & 7.62 \\
\hline $95 \%$ percentile of ef. total $\left(\mathrm{gN} / \mathrm{m}^{3}\right)$ & 15.77 & 15.73 & 19.07 & 18.6 & 20.03 & 19.61 \\
\hline $95 \%$ percentile of ef. TSS $\left(g C O D / m^{3}\right)$ & 20.18 & 19.70 & 21.70 & 21.6 & 20.78 & 20.76 \\
\hline
\end{tabular}
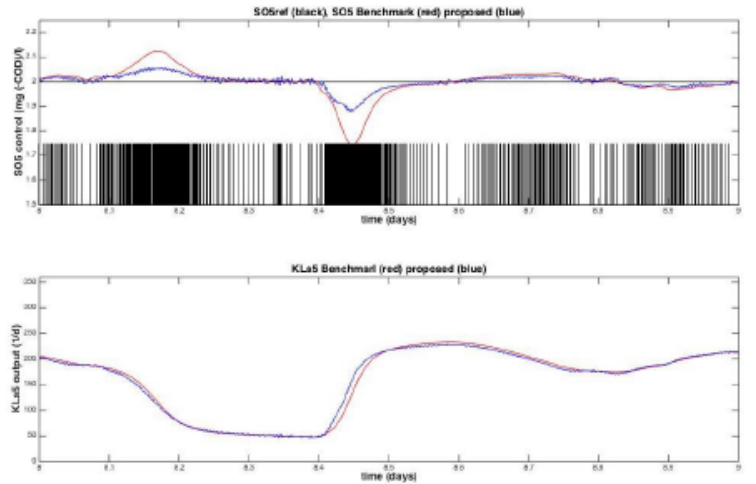

Figure 5: $\mathrm{SO}_{5}$ control loop performance and $K L a_{5}$ for one day showing event generation

lation without need for any other change.

The event-based approach has been compared with the default controllers provided in the benchmark that are implemented as continuous PI controllers. It has been seen that the event-based approach outperforms the continuous one both at loop level and at overall operational level.

As the problem tackled in this paper is, basically, a regulation problem where the controllers task is basically to attenuate the effect of influent load input disturbances, it would also be interesting to study the use of other solutions rather than the
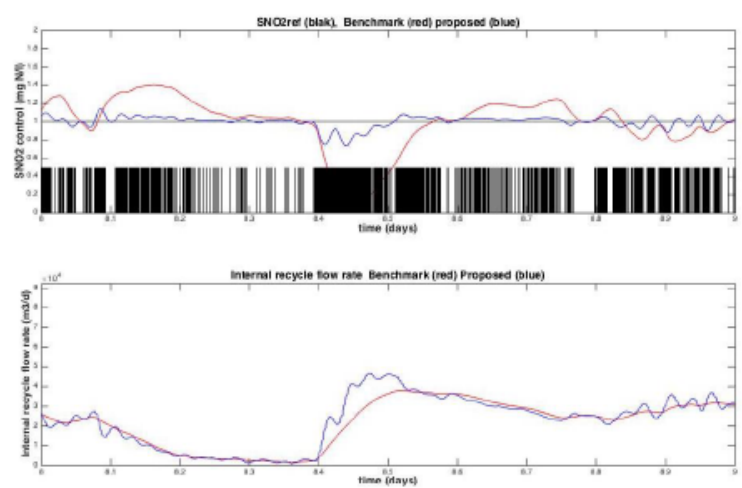

Figure 6: $\mathrm{SNO}_{2}$ control loop performance and $Q_{\text {intr }}$ for one day showing event generation

usual IMC approach that us more aimed at setpoint following. To this end, the direct-synthesis approach for load disturbance will result promising as it also shares the same design principles as the IMC controller.

\section{Acknowledgement}

This work was partially supported by the Spanish Ministry of Economy and Competitiveness program under MINECO/FEDER grant DPI201677271-R 


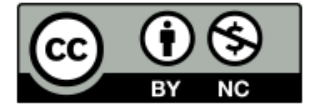

(c) 2018 by the authors. Submitted for possible open access publication under the terms and conditions of the Creative Commons Attribution CC-BY-NC 3.0 license (http://creativecommons.org/licenses/by-nc/3.0/).

\section{References}

[1] R. Vilanova, I. Santín, and C. Pedret, "Control en estaciones depuradoras de aguas residuales: Estado actual y perspectivas," Revista Iberoamericana de Automática e Informática industrial, vol. 14, no. 4, pp. 329-345, 2017.

[2] — , "Control y operación de estaciones depuradoras de aguas residuales: Modelado y simulación," Revista Iberoamericana de Automática e Informática industrial, vol. 14, no. 3, pp. 217-233, 2017.

[3] J. Zeng and J. Liu, "Economic model predictive control of wastewater treatment processes," Industrial \& Engineering Chemistry Research, vol. 54, no. 21, pp. 5710-5721, 2015.

[4] I. Santin, M. Barbu, C. Pedret, and R. Vilanova, "Control strategies for nitrous oxide emissions reduction on wastewater treatment plants operation," Water Research, vol. 125, pp. 466 - 477, 2017.

[5] C. Vlad, M. Sbarciog, M. Barbu, and A. V. Wouwer, "Indirect control of substrate concentration for a wastewater treatment process by dissolved oxygen tracking," Control Eng. Appl. Info, vol. 14 , pp. $38-47,2012$.

[6] D. Vrecko, N. Hvala, and M. Strazar, "The application of model predictive control of ammonia nitrogen in an activated sludge process," Water Science and Technology, vol. 64, no. 5, pp. 11151121, 2011.

[7] A. Capodaglio, A. Callegari, and D. Molognoni, "Online monitoring of priority and dangerous pollutants in natural and urban waters: A stateof-the-art review," Manag. Env. Quality: Int. J, vol. 27 , p. $507 ? 536,2017$.

[8] P. Ingildsen and H. Wendelboe, "Improved nutrient removal using in situ continuous on-line sensors with short response time," Wat. Sci. Technol, vol. 48, p. 95?102, 2013.

[9] J. Alex, L. Benedetti, J. Copp, K. V. Gernaey, U. Jeppsson, I. Nopens, N. Pons, L. Rieger, C. Rosen, J. P. Steyer, P. Vanrolleghem, and S. Winkler, "Benchmark Simulation Model no. 1 (BSM1)," Department of Industrial Electrical Engineering and Automation, Lund University, Tech. Rep., 2008.

[10] X. Du, J. Wang, V. Jegatheesan, and G. Shi, "Dissolved oxygen control in activated sludge process using a neural network-based adaptive pid algorithm," Applied Sciences, vol. 8, no. 2, p. $261,2018$.
[11] H.-g. Han, L. Zhang, and J.-f. Qiao, "Data-based predictive control for wastewater treatment process," IEEE Access, vol. 6, pp. 1498-1512, 2018.

[12] A. Pawlowski, J. Mendoza, J. Guzmán, M. Berenguel, F. Acién, and S. Dormido, "Effective utilization of flue gases in raceway reactor with event-based ph control for microalgae culture," Bioresource technology, vol. 170, pp. $1-9,2014$.

[13] A. Pawlowski, J. L. Guzman, F. Rodríguez, M. Berenguel, J. Sánchez, and S. Dormido, "Simulation of greenhouse climate monitoring and control with wireless sensor network and eventbased control," Sensors, vol. 9, no. 1, pp. 232$252,2009$.

[14] R. Vilanova, "An internal model control approach to event-based control," in 2017 3rd International Conference on Event-Based Control, Communication and Signal Processing (EBCCSP), May 2017, pp. 1-6.

[15] J. B. Copp, "Development of standardised influent files for the evaluation of actived sludge control strategies," IAWQ, IAWQ Scientific and Technical Report, 1999.

[16] H. Vanhooren and K. Nguyen, "Development of a simulation protocol for evaluation of respirometry-based control strategies," University of Gent, Gent, Belgium, Tech. Rep., 1996.

[17] D. E. Rivera, M. Morari, and S. Skogestad, "Internal Model Control. 4. PID controller desing," Ind. Eng. Chem. Des. Dev., vol. 25, pp. 252-265, 1986.

[18] M. Morari and E. Zafirou, Robust Process Control. Englewood Cliffs, NJ, Prentice-Hall, 1989.

[19] M. Beschi, S. Dormido, J. Sanchez, and A. Visioli, "Characterization of symmetric send-on-delta PI controllers," Journal of Process Control, vol. 22, no. 10, pp. 1930-1945, dec 2012.

[20] P. V. Overschee and B. de Moor, "N4SID: subspace algorithms for the identification of combined deterministic-stochastic systems." Automatica, vol. 30, pp. 75-93, 1994.

[21] I. Santin, C. Pedret, and R. Vilanova, "Applying variable dissolved oxygen set point in a two level hierarchical control structure to a wastewater treatment process," Journal of Process Control, vol. 28, pp. 40-55, 2015. 